CONF-960502-.7

SAND96-0784C

\title{
EFFECT OF HYDROGEN ON Ca AND \\ Mg ACCEPTORS IN GaN
}

\author{
J. W. Lee, S. J. Pearton \\ University of Florida, Ganiesville FL 32611 \\ J. C. Zolper \\ Sandia National Laboratories, Albuquerque NM 87185 \\ and \\ R. A. Stall
}

EMCORE Corporation, Somerset NJ 08873

The influence of minority carrier injection on the reactivation of hydrogen passivated $\mathrm{Mg}$ in $\mathrm{GaN}$ at $175^{\circ} \mathrm{C}$ has been investigated in p-n junction diodes. The dissociation of the neutral $\mathrm{MgH}$ complexes is greatly enhanced in the presence of minority carrier and the reactivation process follows second order kinetics. Conventional annealing under zero-bias conditions does not produce $\mathrm{Mg}-\mathrm{H}$ dissociation until temperatures $\geq$ $450^{\circ} \mathrm{C}$. These results provide an explanation for the e-beam induced reactivation of $\mathrm{Mg}$ acceptors in hydrogenated GaN. Exposure to a hydrogen plasma at $250^{\circ} \mathrm{C}$ of p-type $\mathrm{GaN}(\mathrm{Ca})$ prepared by either $\mathrm{Ca}^{+}$-or $\mathrm{Ca}^{+}$plus $\mathrm{P}^{+}$coimplantation leads to a reduction in sheet carrier density of approximately an order of magnitude $\left(1.6 \times 10^{12} \mathrm{~cm}^{-2}\right.$ to $\left.1.8 \times 10^{11} \mathrm{~cm}^{-2}\right)$, and an accompanying increase in hole mobility $\left(6 \mathrm{~cm}^{2} / \mathrm{Vs}\right.$ to $\left.18 \mathrm{~cm}^{2} / \mathrm{Vs}\right)$. The passivation process can be reversed by post-hydrogenation annealing at $400-500^{\circ} \mathrm{C}$ under a $\mathrm{N}_{2}$ ambient. This reactivation of the acceptors is characteristic of the formation of neutral $(\mathrm{Ca}-\mathrm{H})$ complexes in the $\mathrm{GaN}$. The thermal stability of the passivation is similar to that of $\mathrm{Mg}-\mathrm{H}$ complexes in material prepared in the same manner (implantation) with similar initial doping levels. Hydrogen passivation of acceptor dopants in GaN appears to be a ubiquitous phenomenon, as it is in other p-type semiconductors.

In both $\mathrm{Si}$ and $\mathrm{GaAs}{ }^{(9-12)}$, injection of minority carriers either by forward biasing of a diode structure or illumination with above-bandgap light produces dissociation of neutral acceptor-hydrogen or donor-hydrogen complexes at temperatures at which they are normally thermally stable. While the details of the reactivation process are not

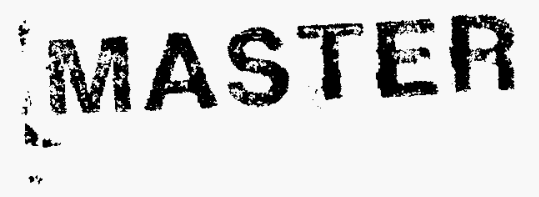

DISTAIBUTION OF THIS DOCUMENT IS UNLIMITED NPM 


\section{DESCLAMIBR}

Portions of this document mag be illegible in eleetronic image produrts. Images are: produced from the best available original document. 
clearly established, it is expected that for an acceptor A the reactions likely can be described by

$$
\begin{aligned}
& (\mathrm{AH})^{\circ} \leftrightarrow \mathrm{A}^{-}+\mathrm{H}^{+} \\
& \mathrm{H}^{+}+\mathrm{e}^{-} \leftrightarrow \mathrm{H}^{\circ}
\end{aligned}
$$

The neutral hydrogen most likely forms diatomic or larger clusters with other neutral or charged hydrogen species. ${ }^{(13)}$

There has recently been a lot of interest in the stability of hydrogen passivated $\mathrm{Mg}$ acceptors in $\mathrm{GaN}$. Amano et al. ${ }^{(14)}$ first demonstrated p-type conductivity in $\mathrm{GaN}$ $(\mathrm{Mg})$ after an e-beam irradiation process near room temperature and later Nakamura et al. (15) showed that simple thermal annealing at $\sim 700^{\circ} \mathrm{C}$ also reactivated the $\mathrm{Mg}$ acceptors. It is clear that atomic hydrogen remaining in the $\mathrm{GaN}$ after growth by metal organic chemical vapor deposition (MOCVD) with $\mathrm{NH}_{3}$ and $\left(\mathrm{CH}_{3}\right)_{3} \mathrm{Ga}$ precursors attaches to the $\mathrm{Mg}$, forming neutral complexes. Currently all $\mathrm{Mg}$-doped $\mathrm{GaN}$ grown by MOCVD is annealed under $\mathrm{N}_{2}$ for $20-60 \mathrm{mins}$ at $-700^{\circ} \mathrm{C}$ to achieve the full level of $\mathrm{p}$ type conductivity. ${ }^{(16)}$ The mechanism for acceptor activation during the e-beam irradiation process has not been studied in detail to date. To establish that minority carrier enhanced debonding of $\mathrm{Mg}-\mathrm{H}$ complexes in $\mathrm{GaN}$ is responsible for this phenomenon, we examined the effect of forward biasing in hydrogenated p-n junctions. We find that the reactivation of passivated acceptors obeys second order kinetics and that the dissociation of the $\mathrm{Mg}-\mathrm{H}$ complex is greatly enhanced under minority carrier injection conditions.

The sample were grown an $\mathrm{c}-\mathrm{Al}_{2} \mathrm{O}_{3}$ by $\mathrm{MOCVD}$ using a rotating disk reactor. ${ }^{(16)}$ After chemical cleaning of the substrate in both acids $\left(\mathrm{H}_{2} \mathrm{SO}_{4}\right)$ and solvents (methanol, acetone), it was baked at $1100^{\circ} \mathrm{C}$ under $\mathrm{H}_{2}$. A thin ( $\left.\leq 300 \AA\right) \mathrm{GaN}$ buffer was grown at $510^{\circ} \mathrm{C}$, before growth of $\sim 1 \mu \mathrm{m}$ undoped material, $0.5 \mu \mathrm{m}$ of $\mathrm{GaN}(\mathrm{Mg})$ with a carrier density of $\mathrm{p}^{\sim} 1.5 \times 10^{17} \mathrm{~cm}^{-3}$ after $700^{\circ} \mathrm{C}$ annealing and $0.3 \mu \mathrm{m}$ of $\mathrm{GaN}$ (Si) with a carrier density of $5 \times 10^{18} \mathrm{~cm}^{-3}$. Some of the sample were hydrogenated by annealing under $\mathrm{NH}_{3}$ for 30 mins at $500^{\circ} \mathrm{C}$. ${ }^{(15)}$ This produces passivation of the $\mathrm{Mg}$ acceptors but has little effect on the Si donors.

Mesa p-n junction diodes were processed by patterning $500 \mu \mathrm{m}$ diameter $\mathrm{TiAl}$ ohmic contacts on the $\mathrm{n}$-GaN by lift-off and then performing a self-aligned dry etch with an Electron Cyclotron Resonance $\mathrm{BCl}_{3} / \mathrm{Ar}$ plasma to exposure the p-type $\mathrm{GaN}^{(11)}$ E-beam evaporated NiAu was patterned by lift-off to make ohmic contact to the p-type material. The carrier profiles in the p-type layer were obtained from $10 \mathrm{kHz}$ capacitancevoltage measurements at room temperature. Anneals were carried out in the dark at $175^{\circ} \mathrm{C}$ under two different types of condition. In the first, the diode was in the opencircuit configuration, while in the second the junction was forward biased at $9 \mathrm{~mA}$ to inject electrons into the p-type GaN. After each of these treatments the samples were 
returned to $300 \mathrm{~K}$ for re-measurement of the net electrically active acceptor profile in this layer.

Figure 1 shows a series of acceptor concentration profiles measured on the same p-n junction sample, after annealing at $175^{\circ} \mathrm{C}$ under forward bias conditions. After the $\mathrm{NH}_{3}$ hydrogenation treatment the electrically active acceptor density decreased from $1.5 \times 10^{17} \mathrm{~cm}^{-3}$ to $-6-7 \times 10^{16} \mathrm{~cm}^{-3}$. If the subsequent annealing was carried in the opencircuit configuration there was no change in the carrier profile for periods up to $20 \mathrm{hr}$ at $175^{\circ} \mathrm{C}$. By sharp contrast Figure 1 shows that for increasing annealing times under minority carrier injection conditions there is a progressive reactivation of the $\mathrm{Mg}$ acceptors with a corresponding increase in the hole concentration. After $1 \mathrm{hr}$, the majority of these acceptors have been reactivated. Clearly therefore, the injection of electrons has a dramatic influence on the stability of the $\mathrm{MgH}$ complexes. The $\mathrm{Mg}$ reactivation has a strong dependence on depth into the p-type layer, which may result from the diffusion distance of the injected electrons prior to recombination. We rule out heating of the sample during forward biasing as being a factor in the enhanced dissociation of the neutral dopant-hydrogen complexes. The samples were thermally bonded to the stainless steel stage and the junction temperature rise is expected to be minimal $\left(\leq 10^{\circ} \mathrm{C}\right)$. Moreover from separate experiments we found that reactivation of the $\mathrm{Mg}$ did not begin until temperatures above $-450^{\circ} \mathrm{C}$ under zero-bias conditions.

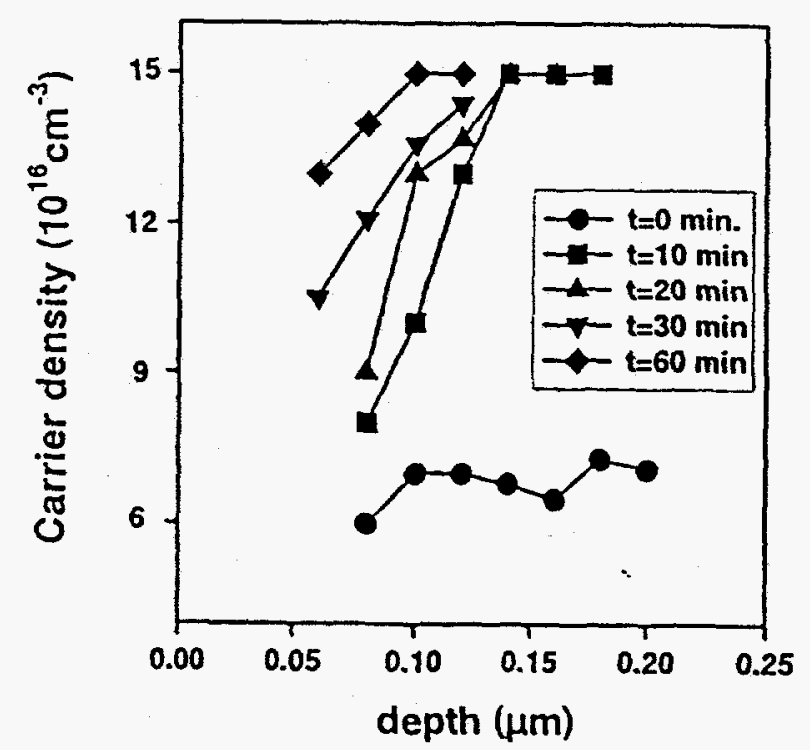

Figure 1. Carrier concentration profiles in hydrogenated $\mathrm{GaN}(\mathrm{Mg})$, after annealing for various times at $175^{\circ} \mathrm{C}$ under forward bias conditions.

\section{DISCLAIMER}

\footnotetext{
This report was prepared as an account of work sponsored by an agency of the United States Government. Neither the United States Government nor any agency thereof, nor any of their employees, makes any warranty, express or implied, or assumes any legal liability or responsibility for the accuracy, completeness, or usefulness of any information, apparatus, product, or process disclosed, or represents that its use would not infringe privately owned rights. Reference herein to any specific commercial product, process, or service by trade name, trademark, manufacturer, or otherwise does not necessarily constitute or imply its endorsement, recommendation, or favoring by the United States Government or any agency thereof. The views and opinions of authors expressed herein do not necessarily state or reflect those of the United States Government or any agency thereof.
} 
Previous experiments on minority carrier enhanced reactivation of hydrogen passivated dopants in $\mathrm{Si}^{(5)}$ and $\mathrm{GaAs}^{(12)}$ have found that for long annealing times the kinetics can be described by a second-order equation

$$
\mathrm{d}\left[\mathrm{N}_{\mathrm{A}}-\mathrm{N}(\mathrm{t})\right] / \mathrm{dt}=\mathrm{C}\left[\mathrm{N}_{\mathrm{A}}-\mathrm{N}(\mathrm{t})\right]^{2}
$$

where $\mathrm{N}_{\mathrm{A}}$ is the uniform $\mathrm{Mg}$ acceptor concentration in the non-hydrogenated sample, $\mathrm{N}(\mathrm{t})$ is the acceptor concentration in the hydrogenated $\mathrm{GaN}$ after forward bias annealing for time $t$ and $C$ is a second order annealing parameter.

In order to quantitatively analyze the reactivation kinetics of the $\mathrm{Mg}-\mathrm{H}$ complexes in $\mathrm{GaN}$, we measured the inactive acceptor concentration $\mathrm{N}_{\mathrm{A}}-\mathrm{N}(\mathrm{t})$ at a depth of $0.1 \mu \mathrm{m}$ in the $\mathrm{p}-\mathrm{GaN}$ layer. Figure 2 shows that there is a linear relationship between $[\mathrm{Na}-\mathrm{N}(\mathrm{t})]^{-1}$ and annealing time $\mathrm{t}$, confirming that the reactivation process can be described by a second-order equation with $\mathrm{C}=4 \times 10^{-20} \mathrm{~cm}^{3} \mathrm{~s}^{-1}$. This value is consistent with those obtained in $\mathrm{Si}$ and $\mathrm{GaAs}$ where minority carrier enhanced dopant reactivation has atso been reported. In that work, the annealing parameter was found to depend on the injected minority carrier density. Moreover, for short annealing times it was found that the dopant reactivation occurred at a faster rate than predicted by the second-order equation for very short annealing times, and that the annealing process was rate-limited by the formation of stable, electrically inactive diatomic $\mathrm{H}$ species. At this point there have not been enough studies of the various states of hydrogen in $\mathrm{GaN}$ as determined by infra-red spectroscopy, channeling or secondary ion mass spectrometry for us to conclude anything about the ultimate fate of the atomic hydrogen once it has dissociated from the $\mathrm{Mg}-\mathrm{H}$ complex, but it is likely that it then reacts with other hydrogen atoms to form diatomic or larger clusters. A strong dependence of reactivation rate on injected minority carrier density would indicate the presence of a charge state for hydrogen and therefore influence the conversion of $\mathrm{H}^{+}$into the neutral state and then into the final hydrogen complexes.

The fact that the $\mathrm{MgH}$ complexes are unstable against minority carrier injection has implications for several GaN-based devices. Firstly, in a laser structure the high level of carrier injection would rapidly dissociate any remaining $\mathrm{Mg}-\mathrm{H}$ complexes and thus would be forgiving of incomplete removal of hydrogen during the post-growth annealing treatment. In a heterojunction bipolar transistor the lower level of injected minority carriers would also reactivate passivated $\mathrm{Mg}$ in the base layer, leading to an apparent time-dependent decrease in gain as the device was operated. 


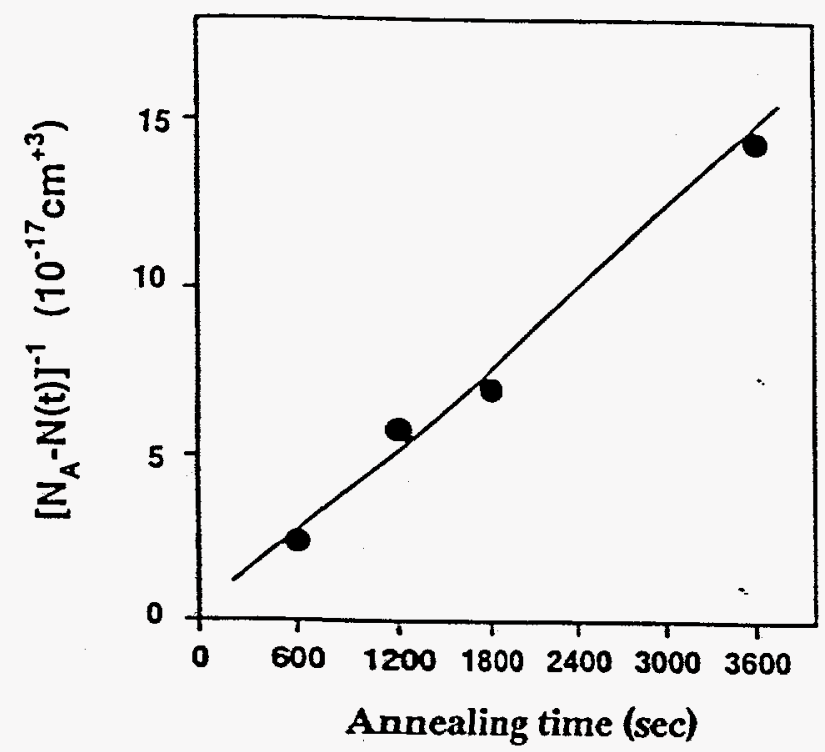

Figure 2. Plot of inverse net inactive $\mathrm{Mg}$ concentration determined from Figure 1 at a depth of $0.1 \mu \mathrm{m}$, as a function of forward bias annealing time.

Theoretical considerations have suggested that $\mathrm{Ca}$ might be a shallower acceptor in $\mathrm{GaN}$ than $\mathrm{Mg} .{ }^{(18)}$ We have recently realized p-type doping of $\mathrm{GaN}$ using implantation of $\mathrm{Ca}^{+}$alone, or a co-implantation of $\mathrm{Ca}^{+}$and $\mathrm{P}^{+}$, followed by rapid thermal annealing at $\triangle 1100^{\circ} \mathrm{C} .^{(19)}$ While the activation efficiency of $\mathrm{Ca}$ in both implant schemes was $\sim 100 \%$, temperature-dependent Hall measurements showed that the ionization level of $\mathrm{Ca}$ was $-169 \mathrm{meV}$ similar to that of $\mathrm{Mg}$. An Arrhenius plot of the sheet hole concentration from in Ca-implanted sample annealed at $1150^{\circ} \mathrm{C}$ shows the activation level to be $169 \pm 12 \mathrm{meV}$ (Figure 3). The $\mathrm{Ca}$ atomic profile was thermally stable to temperatures up to $1125^{\circ} \mathrm{C}$. Since $\mathrm{Mg}$ has a substantial memory effect in stainless steel epitaxial reactors (or in gas lines leading to quartz chamber systems), $\mathrm{Ca}$ may be a useful alternative p-dopant for epitaxial growth of laser diode or heterojuction bipolar transistor structures in which junction placement, and hence control of dopant profiles, is of critical importance.

In considering Ca-doped $\mathrm{GaN}$ for device applications it is also necessary to understand the role of hydrogen, since there is always a ready supply of atomic hydrogen available from $\mathrm{NH}_{3}$, the metalorganic group III source (typically $\left(\mathrm{CH}_{3}\right)_{3} \mathrm{Ga}$ ) of from the gaseous dopant source when using chemical vapor deposition techniques. In this letter we show that $\mathrm{Ca}$ acceptors in $\mathrm{GaN}$ are also readily passivated by atomic hydrogen at low temperature $\left(250^{\circ} \mathrm{C}\right)$, but they can be reactivated by thermal annealing at $5500^{\circ} \mathrm{C}$ for $1 \mathrm{~min}$ in lightly-doped $\left(3 \times 10^{17} \mathrm{~cm}^{-3}\right)$ materials. As the carrier density is restored by such annealing treatments there is a corresponding decrease in hole mobility, indicating that there is a true passivation and not just compensation of the $\mathrm{Ca}$ acceptors by the hydrogen. 


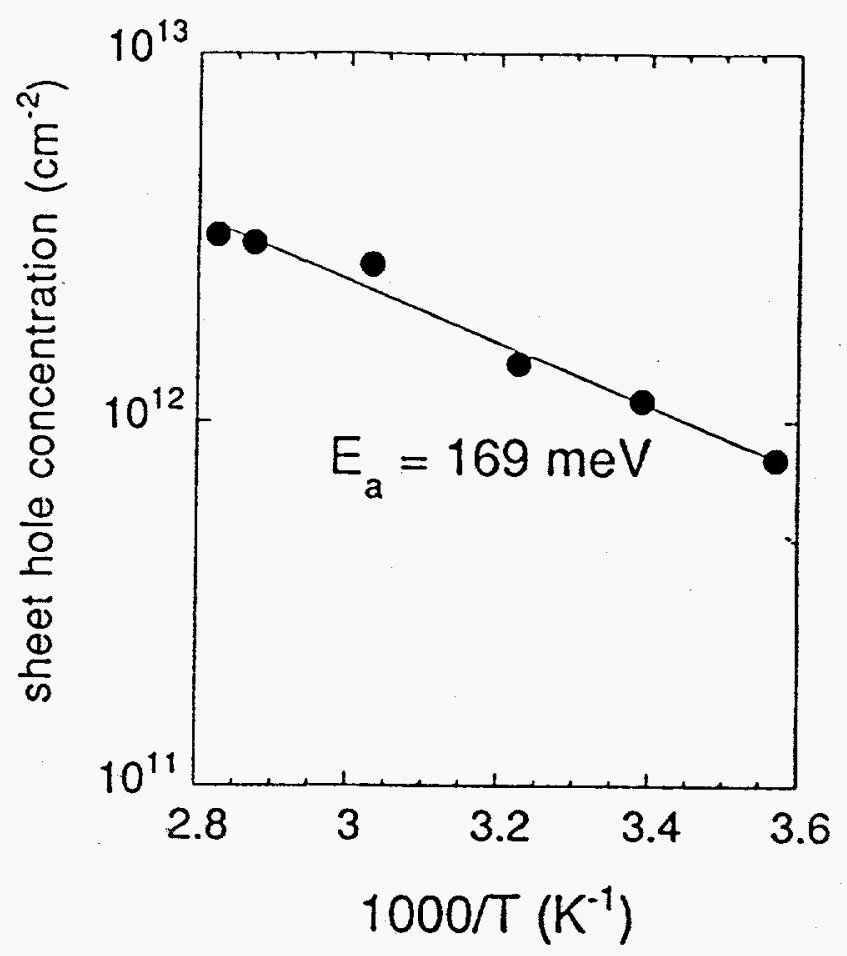

Figure 3. Arrhenius plot of sheet hole density in Ca-implanted GaN. The acivation energy is $169 \pm 12 \mathrm{meV}$

Nominally undoped $\left(\mathrm{n}<3 \times 10^{16} \mathrm{~cm}^{-3}\right) \mathrm{GaN}$ was grown on double-side polished c- $-\mathrm{Al}_{2} \mathrm{O}_{3}$ substrates prepared initially by $\mathrm{HCl} / \mathrm{HNO}_{3} / \mathrm{H}_{2} \mathrm{O}$ cleaning and an in-situ $\mathrm{H}_{2}$ bake at $1070^{\circ} \mathrm{C} .{ }^{(20)} \mathrm{A} \mathrm{GaN}$ buffer $\leq 300 \AA$ thick was then grown at $-500^{\circ} \mathrm{C}$ and crystallized by ramping the temperature to $1040^{\circ} \mathrm{C}$ where trimethylgallium and ammonia are again used to grow the $2 \mu \mathrm{m}$ thick epitaxial layer. The materials properties have been discussed in detail earlier, ${ }^{(20,21)}$ but in brief the double crystal $x$-ray full width at half maxima are -300 arc $\mathrm{sec}$ and the total defect density (threading dislocations, stacking faults) apparent in plan view transmission electron microscopy was typically 2$4 \times 10^{9} \mathrm{~cm}^{-2}$. The as-grown films are featureless, transparent and have strong bandedge $(3.47 \mathrm{eV})$ luminescence.

${ }^{40} \mathrm{Ca}$ ions were implanted at $180 \mathrm{keV}$ and a dose of $5 \times 10^{14} \mathrm{~cm}^{-2}$. In some cases, a co-implant of $\mathrm{P}^{+}$to the same dose at an energy of $130 \mathrm{keV}$ was performed to try to enhance the substitutional fraction of Ca upon subsequent annealing in analogy to the case of $\mathrm{Mg}$ implantation in $\mathrm{GaN} .{ }^{(22)}$ For the case of $\mathrm{Ca}$ we found there was little additional activation as a result of the W-implant. After rapid annealing at $1150^{\circ} \mathrm{C}$ for 15 secs under $\mathrm{N}_{2}$ in a face-to-face geometry we measured sheet carrier densities of p $1.6 \times 10^{12} \mathrm{~cm}^{-2}$ with a mobility at $300 \mathrm{~K}$ of $6 \mathrm{~cm}^{2} / \mathrm{Vs}$. Arrhenius plots of the hole density showed an ionization level of $16 \mathrm{~g} \mathrm{meV}$ for the $\mathrm{Ca}$ in $\mathrm{GaN}$. Samples with alloyed HgIn 
ohmic contacts were exposed to an Electron Cyclotron Resonance (ECR) $\mathrm{H}_{2}$ or $\mathrm{H}_{2}$ plasma $(2.45 \mathrm{GHz})$ with $850 \mathrm{~W}$ forward power and a pressure of $10 \mathrm{mT}$ Torr. The exposure time was $30 \mathrm{~min}$ at $250^{\circ} \mathrm{C}$, and the temperature was lowered to room temperature with the plasma on the sheet carrier density and hole mobility at $300 \mathrm{~K}$ were obtained from Van der Pauw geometry Hall measurements. Post hydrogenation annealing was performed between $100-500^{\circ} \mathrm{C}$ for $60 \mathrm{sec}$ under flowing $\mathrm{N}_{2}$ with the ohmic contacts already in place.

The initial $\mathrm{H}_{2}$ plasma exposure caused a reduction in sheet hole density of approximately an order of magnitude, as shown in Figure 4. No change in electrical properties were observed in the He-plasma treated samples, showing that pure ion bombardment effects are insignificant and the chemical interaction of hydrogen with the $\mathrm{Ca}$ acceptors is responsible for the conductivity changes. Post-hydrogenation annealing had no effect on the hole density up to $300^{\circ} \mathrm{C}$, while the initial carrier concentration was essentially fully restored at $500^{\circ} \mathrm{C}$. Assuming the passivation mechanism is formation of neutral $\mathrm{Ca}-\mathrm{H}$ complexes, then the hole mobility should increase upon hydrogenation. This is indeed the case, as-shown in Figure 5. Note that the mobility decreases to its initial value with post-hydrogenation annealing. If the carrier reduction were due to introduction of compensating defects or impurities, then the hole mobility would decrease, which is not observed.

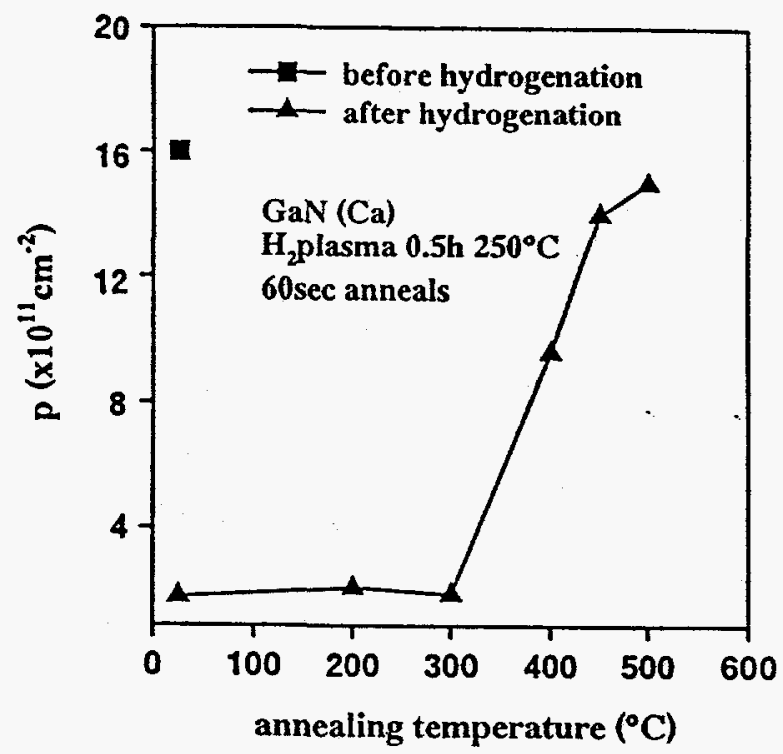

Figure 4. Sheet hole density at $300 \mathrm{~K}$ in hydrogenated $\mathrm{GaN}(\mathrm{Ca})$ as a function of subsequent annealing temperature. 


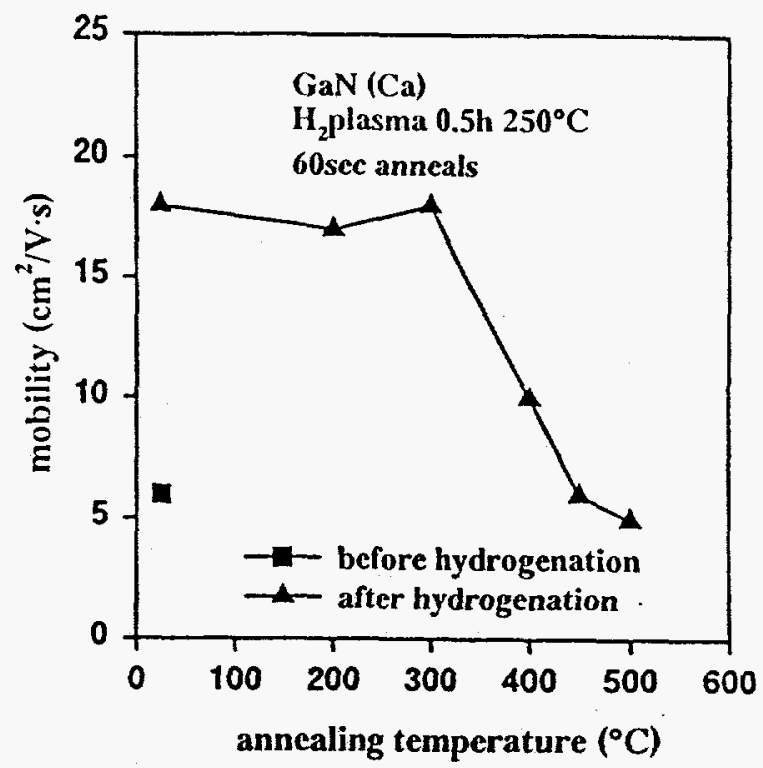

Figure 5. Hole mobility at $300 \mathrm{~K}$ is hydrogenated $\mathrm{GaN}(\mathrm{Ca})$ as a function of subsequent a nnealing temperature.

In other p-type III-V semiconductors it is generally accepted that atomic hydrogen is predominantly in a positive charge state with the donor level being around midgap. If a similar mechanism exists in GaN then the initial Coulombic attraction between ionized acceptor and hydrogen leads to formation of a neutral close pair, i.e.

$$
\mathrm{Ca}^{-}+\mathrm{H}^{+} \leftrightarrow(\mathrm{Ca}-\mathrm{H})^{0}
$$

The existence of the neutral complex should be verified by observation of a vibrational band, ${ }^{(23)}$ but to obtain the sensitivity needed for such a measurement will require a relatively thick epitaxial layer of Ca-doped $\mathrm{GaN}$. Our present implanted samples do not have a sufficient $\mathrm{Ca}$ density-times-thickness product to be suitable for infra-red spectroscopy.

If the dissociation of the $\mathrm{Ca}-\mathrm{H}$ species is a first-order process then the reactivation energy from the data in Figure 4 is $-2.2 \mathrm{eV}^{(24)}$ assuming a typical attempt frequency of $10^{14} \mathrm{~s}^{-1}$ for bond breaking processes. This is similar to the thermal stability of $\mathrm{Mg}-\mathrm{H}$ complexes in $\mathrm{GaN}$ which we prepared in the same manner (implantation) with similar doping levels. In thicker, more heavily doped samples, the apparent thermal stability of hydrogen passivation is much higher because of the increased probability of retrapping of hydrogen at other acceptor sites. ${ }^{(24)}$ This is why for thick, heavily doped $\left(\mathrm{p}>10^{18} \mathrm{~cm}^{-3}\right) \mathrm{GaN}(\mathrm{Mg})$ a post-growth anneal of at least $700^{\circ} \mathrm{C}$ for $60 \mathrm{~min}$ is employed to ensure complete dehydrogenation of the $\mathrm{Mg} .{ }^{(21,25)}$ True reactivation energies can only be determined in reverse-biased diode samples where the strong electric fields present sweep the charged hydrogen out of the depletion region and minimizes retrapping at the acceptors. ${ }^{(26)}$ 
In summary, we have shown that hydrogen passivated $\mathrm{Mg}$ acceptors in $\mathrm{GaN}$ may be reactivated at $175^{\circ} \mathrm{C}$ by annealing under minority carrier injection conditions. The reactivation follows a second order kinetics process in which the $(\mathrm{MgH})^{\circ}$ complexes are stable to $\geq 450^{\circ} \mathrm{C}$ in thin, highly-doped GaN layers. In thicker, more heavily doped layers where retrapping of hydrogen at the $\mathrm{Mg}$ acceptors is more prevalent, the apparent thermal stability of the passivation is higher and annealing temperatures up to $700^{\circ} \mathrm{C}$ may be required to achieve full activation of the $\mathrm{Mg}$. Our results suggest the mechanism for $\mathrm{Mg}$ activation in e-beam irradiated $\mathrm{GaN}$ is minoritycarrier enhanced debonding of the hydrogen. Hydrogen passivation of acceptors in $\mathrm{GaN}$ occurs for several different dopant impurities and that post-growth annealing will also be required to achieve full electrical activity in Ca-doped material prepared by gasphase deposition techniques. The thermal stability of the passivation is similar for $\mathrm{Ca}-\mathrm{H}$ and $\mathrm{Mg}-\mathrm{H}$ complexes, with apparent reactivation energies of $-2.2 \mathrm{eV}$ in lightly-doped $\left(\sim 10^{17} \mathrm{~cm}^{-3}\right)$ material.

\section{ACKNOWLEDGMENTS}

The work at UF is partially supported by an NSF grant (DMR-9421109) and an ONR URI (N00014-92-3-1895). The work at Sandia is supported by DOE contract DEAC04-94AL85000, while that at EMCORE is partially supported by a grant from BMDO administered through ONR (M. Yoder).

\section{REFERENCES}

1. S. K. Estreicher, Mat. Sci. Eng. Rep. 14319 (1995).

2. C. H. Seager and R. A. Anderson, Appl. Phys. Lett. 631531 (1993).

3. C. H. Seager and R. A. Anderson, Solid State Commun. 76285 (1990).

4. A. J. Tavendale, A. A. Williams, D. Alexiev and S. J. Pearton, Mat. Res. Soc. Symp. Proc. Vol. 59469 (1985).

5. T. Zundel, J. Weber and L. Tilly, Physica B170 361 (1991).

6. C. H. Seager and R. A. Anderson, Appl. Phys. Lett. 29585 (1991).

7. Y. Kamiura, M. Yoneta, Y. Nishiyama and F. Hashimoto, J. Appl. Phys. 723394 (1992).

8. M. Yoneta, Y. Kamiura and F. Haskimoto, J. Appl. Phys. 701295 (1991).

9. I. Szafranek, S. S. Bose and G. E. Stillman, Appl. Phys. Lett. 551205 (1989).

10. I. Szafranek and G. E. Stillman, J. Appl. Phys. 683554 (1990).

11. A. J. Tavendale, S. J. Pearton, A. A. Williams and D. Alexiev, Appl. Phys. Lett. 56 1457 (1990).

12. A. W. R. Leitch, Th. Prescha and J. Weber, Phys. Rev. B. 445912 (1991).

13. S. J. Pearton, J. W. Corbett and M. Stavola, Hydrogen in Crystalline Semiconductors

(Springer-Verlag, Heidelberg 1992). 
14. H. Amano, M. Kito, K. Hiramatsu and I. Akasaki, Jap. J. Appl. Phys. 28 L112 (1989).

15. S. Nakamura, N. Iwasa, M. Senoh and T. Mukai, Jap. J. Appl. Phys. 311258 (1992).

16. C. Yuan, T. Salagaj, A. Gurary, P. Zawadzki, C. S. Chern, W. Kroll, R. A. Stall, Y. Li, M. Schurman, C.-Y. Hwang, W. E. Mayo, Y. Lu, S. J Pearton, S. Krishnankutty and R. M. Kolbas, J. Electrochem. Soc., 142 L163 (1995).

17. S. J. Pearton, C. R. Abernathty and F. Ren Appl. Phys. Lett. 642294 (1994).

18 S, Strite, Jap. J. Appl. Phys. 33 L699 (1994).

19, J. C. Zolper, R. G. Wilson, S. J. Pearton and R. A. Stall (to be published). 20. C. Yuan, T. Sulagaj, A. Gurary, A. G. Thompson, W. Knoll, R. A. Stall, C. Y. Hwang, M. Schurmana, Y. Li, W. E. Mayo, Y. Lu, S. Krishnankutty, I, K. Shmagin, R. M. Kolbas and S. J. Pearton, J. Vac. Sci. Technol. B 132075 (1995).

21. C. Yuan, T. Sulagaj, A. Gurary, P. Zawadzki, C. S. Chern, W. Kroll, R. A. Stall, Y. Li, M. Schurman, C. -Y. Hwang, W. E. Mayo, Y. Lu, S. J. Pearton, S. Krishnancutty and R. M. Kolbas, J..Electrochem. Soc. 1422163 (1995).

22. S. J. Pearton, C. B. Vartuli, J. C. Zolper, C. Yuan and R. A. Stall, Appl. Phys. Lett 671435 (1995).

23. M. Stavola, Mat. Sci. For. 148/149 251 (1994).

24. see for example, Hydrogen in Compound Semiconductors, ed. S. J. Pearton 